\title{
Translation as 'Trans- Sica' and 'False Compare': Preserving the Future 'Afterlife' of Contrastive Literature
}

\author{
Mounir Ben Zid \\ Sultan Qaboos University \\ College of Arts \& Social Sciences, English Department \\ P.O.box 42, Postal Code 123, Al Khod \\ Muscat, Sultanate of Oman
}

Received: 06-06- 2013

doi:10.7575/aiac.ijclts.v.1n.2p.11
Accepted: 20-06-2013

Published: 31-07- 2013

URL: http://dx.doi.org/10.7575/aiac.ijclts.v.1n.2p.11

\begin{abstract}
It is a common practice for translators to make deletions or additions in a literary work due to personal cultural bias or to avoid embarrassing their countrymen with immoral or obscene images and ideas. This paper questions the role of translation as a critical approach and decries this source text "improvement" as a mistranslation and silencing of the authorial voice. An incorrect translation, rather than being a means of bringing two cultures together, does a disservice to comparative studies and harm to the author and his cultural idiosyncrasies. In addressing distortions arising from cultural and moral bias in Arab translations of Shakespeare's Sonnet 18, the paper discusses how Bakri Al- Azzam introduced an oriental undertone, silenced Shakespeare's voice, changed the speaker's gender, and transformed Shakespeare into an Arab classic poet - all to align the sonnet with the cultural outlook of Arabs at the expense of Shakespeare's identity, culture, and Western aesthetics.
\end{abstract}

Keywords: Comparative literature, translation, contrastive literature, cultural values, identity, trans-assassination

\section{Introduction}

The main objective of this paper is not to describe the death and "identity crisis" the discipline of comparative literature has constantly confronted ever since the term was coined. Nevertheless, the study finds it necessary to offer a sketch of the current status of comparative literature as well as an overview of the elements that contributed to its current crisis. The overarching concern of the present study, however, is to address the question of whether translation can be a vital discipline in contributing to the future of comparative literature - in crossing the boundaries of languages and cultures and in manipulating the fame and reputation of an author. Its main purpose is to arbitrate the dominant trends of and approaches to the future role of comparative literature and examine whether translation can endow the discipline with an "afterlife," one with better status and greater self-confidence.

Being no Tiresias who has seen it all, the study refrains from making predictions for the future of comparative literature. It is sufficient for my purposes to point out that there is currently little agreement regarding the future status of the discipline and that the response to this controversy is materialized in a torrent of paradigms, all trying to offer possible solutions to the problem; as a result, a rich body of work has emerged in response to the death and profound crisis in comparative literature.

According to the prophets of gloom and doom, the état presént of comparative literature has been characterized by stagnation, uncertainty, and a sense of crisis, as Albert Guerard's (1958) exclamatory comment suggests: "How and when shall we commit suicide? Not just yet [... ] Let us keep alive as comparatists; but let us 'bore from within' rather than seek to create a separate establishment" (p. 75).

Lamenting the lack of "sécurité," the uncertainty and the vastness of comparative literature's content, as well as the ambiguity in its definition, aims, and methodology, Peter Brooks also maintains that he has never been "sure what the field or the discipline" was (as cited in Bernheimer, 1995, p. 98).

Pessimistic statements on the future of comparative literature are also exemplified by influential scholars like Emily Apter, who does not hide her skepticism and disbelief in matters of literary comparatism. In the chapter's opening line, "je ne crois pas beaucoup a la littérature comparée," she argues that comparing literary works through translation is a disaster for great poems (as cited in Saussy, 2006, p. 56).

The status of the discipline can better be described by using William Butler Yeats' famous verse in "The Second Coming," that "things fall apart, the centre cannot hold; [and that] mere anarchy is loosed upon the world" of comparative literature (as cited in Albright, 1990). 
Rejecting such a negative perspective on the status and future of comparative literature, the present study subscribes to the premise that the discipline, despite Bassnett's (1993) flawed prediction that it "is in one sense dead (p. 47), is having a new beginning and that the discipline "has, in a sense, won battles" (Saussy, 2006, p. 3) - that it is not in crisis at all and that the impasse it is experiencing should be viewed as a new departure, "a turning point, a revolutionary instant in which we move from an old to a renewed condition" (Docherty, 2006, p. 2).

Thus, the comparative literature approach endorsed by this study is an optimistic paradigm that opens up new developments and possibilities for the future of the discipline and suggests a model that "contains both in theoretical and in pragmatic terms conditions which would be applicable to the situation in Western European countries and follows postulates of a New Comparative Literature" (Tötosy, 1998, p. 123).

Contrary to the negative view of some comparatists and scholars who take pain to extinguish the controversy or to conceive the future of comparative literature, this paper maintains that the survival of the discipline is possible and that it is not in finding answers to all questions but rather in preserving the polemics and controversy over its nature, name, aims, and methodology. The future of the discipline, in David Ferris' view, is in its 'indiscipline' because it is in "that relentless questioning of aims and contexts [that] resides ... one of the most important strengths of all the humanistic disciplines" (as cited in Yu, 2006, p. 53).

Other scholars hold an identical view that an old and outworn version of comparative literature has died and, in its place, another is rising to bring the field forward and to study the encounter of foreign and host cultures, texts, ideas, and practices.

In a similar vein, Chinese comparatists like Wang Ning (2010) maintain that, despite its apparent crisis and death, comparative literature is not dying but rather growing rapidly and there is still a future for the discipline, as most pessimistic statements refer only to American or European centers.

What appears from the above debate is that the solution to the crisis in comparative literature, if there is any, is not in extinguishing the controversy over its nature, aims, or methodology, or in exploring more interrelationships or avenues, but rather in changing vistas and looking into the interior; the solution is to acquire a fuller understanding of the works of art and transcend the limits of national literature, tear apart boundaries, deconstruct opposition, and open up a fruitful dialogue between different national and international literatures.

Within this new paradigm, comparative literature, while maintaining cultural peculiarities and identities, must become a form of globalization - multidisciplinary and transnational — not tied to national moorings and including not just Eurocentric but also East/West and North/South foci of comparison. In other words, comparative literature should exercise a form of cultural diplomacy, "a universal culture expressed in a universal language and comprehended in a universal mode of thought" (Weisinger \& Joyaux, as cited in Yu, 2006, p. 38).

In this same frame of mind, Claudio Guillen (1993) argues for a comparativist approach that is "sensitive to tensions between the local and the universal, between the specific and the general, thus making links between the two poles ... with the desire to overcome cultural nationalism... and ideological purposes" (as cited in Villanueva, 2011, p. 2-3).

My tentative conclusion is that the future of comparative literature lies in moving away from studying resemblances and parallels and turning its collective attention to differences and contrasts. The basic assumption behind such a contrastive literature paradigm is a rejection of comparison per se or comparing to un-compare since comparison, as the Japanese critique Murakami (1998) stated, entails aesthetic violence and cultural distortions:

Comparative perception, which discovers similitude, inevitably involves exclusion. Exclusion is marginalization. The universal/identical is maintained only through constantly relegating differences to the field of deviation, barbarism, perversion, illegitimacy, abnormality, and inhumanity.(p. 3)

Following this new planetary comparativist approach - which examines national and international literatures without negating or distorting cultural differences and specificities - the study suggests dropping "the comparative" when the discipline ceases to compare and argues in favor of a contrastive approach to literature since the concept of contrasting implies a two-way or a multi-directional activity where both similarities and differences are equally put into play and where cultural diversity is preserved, as Michael Palencia-Roth (1993) stated:

It is the uniqueness of various literatures and texts which has all too often lost to view in comparative literature. Critical methods should be developed and expanded so as to be able to accommodate differences as fruitfully as they already do likenesses. Our methodology should not be ideologically programmed in favor of a universal uniformity in aesthetic values. At the very least, we should recognize that the issue of quality in art is culture-specific. (p. 57)

However, the essential question that begs resolution is whether translation studies can serve contrastive literature as a force for literary renewal and innovation and play a vital role in "jettisoning attempts to define the object of study in any prescriptive way and in focusing instead on the idea of literature, understood in the broadest possible sense, and in recognizing the inevitable interconnectedness that comes from literary transfer" (Bassnett, 2006, p. 10).

\section{Translation and the 'Afterlife' of Contrastive Literature}

In line with the contrastive literature approach supported by the present study, it is my view that translation can serve the discipline as a cultural mediator that facilitates dialogue between literatures and cultures to assure the "afterlife" of a 
work of art, to highlight rather than efface "the differences between languages and cultures" (Benjamin, 1979, as cited in Macedo \& Pereire, 2006, p. 13).

Yet scholars like Stanley Corngold (2005) hold reservations toward the role translation may play in comparative literature studies. He argues that the two fields are different and that:

...while translation means carrying over a piece of foreign language into one's own, "comparison" means being momentarily without one's language, not needing to translate precisely because of one's ability to translate, to step into the other's language without carrying it across, and thus respecting the otherness of languages and cultures. (p. 141)

In his Preface to the Dictionary, Samuel Johnson argues against translation of one's national language and literary works and claims that the duty of all French scholars is to protect their language and "to stop the license of translators, whose influence and ignorance, if it be suffered to proceed, will reduce us to babble a dialect of France" (as cited in Crowley, 1996, p. 63).

Many other scholars express a sense of indeterminacy toward the relevance or usefulness of translation to comparative literature studies, pointing out that translation should be resorted to only in linguistic emergencies since comparatists are more concerned with the originals. Arguing against the use of translation, Thomas Greene laments that "the most disturbing recent trend is the association of comparative literature with literature in translation" (as cited in Bermann, 2009, p. 437).

Nevertheless, and despite some reservation about the role translation can play in comparative literature, considerable agreement exists that translation is the heart of the discipline, an essential and indispensable partner for its future development.

Thus, the paper argues that translation, if adequately implemented, can be of great service to comparative literature; translations of important literary works like Shakespeare's sonnets can constitute a major avenue for the survival and prosperity of the field. Thanks to translation, in fact, many of the literary achievements of a country have found a hearing and even became naturalized in other countries. In this sense, operating as an intermediary function, translation performs a central role within comparative literature studies, both on the level of its theorization and on the level of empiric description of translated literature. In other words, translation endows a literary work with a "continued life" or an "afterlife," without which it might remain dead or marginalized. Asserting that the translator's function is comparable to the author's, Walter Benjamin (1979) points out that translatability:

$\ldots$ is an essential quality of certain works, which is not to say that it is essential that they be translated; it means rather that a specific significance inherent in the original manifests itself in its translatability. (as cited in Venuti, 2000, p. 1)

Similarly, Susan Bassnett (1993) argues that comparative literature and translation are mutually beneficial methods of approaching literature and that, with translation at the center stage, comparative literature can gain more self-confidence and a better status. Therefore, she invites comparatists to "look upon translation studies as the principle discipline from now on, with comparative literature as a valued but subsidiary subject area" (p. 161).

Stressing the primacy of translation, Gramuglio (2006) states that translation is required for any and every act of comparative literature and that it is "a central practice for comparatism, since it locates itself at the meeting point of different languages, literature, and cultures" (as cited in Venturini, 2011, p. 133).

From this perspective, the paper makes a case for an ethics of translation strategy that gives attention to both the original language culture of the text and the target language culture of the translated text; the translator should make the reader uncomfortable with the language in the text and more aware of its preconceived linguistic and cultural expectations. Rather than producing a transparent text, the task of the translator is to preserve domestic cultural attitudes, ethics, and beliefs, and likewise force the reader to recognize their 'foreignness' (Venuti, 1998).

It is interesting to note in this respect that Friedrich Schleiermacher (1999) also suggests that a translator cannot find an equivalent in the target language and must retain "otherness within translation, preserve the linguistic and cultural context of the mother tongue text in the translated foreign language text to as great an extent as possible" (p. 12).

In this same frame of mind, Walter Benjamin (1976) insists that the task of the translator, prior to anything else, is "a movement out towards the other, an act of liberation and a sense of openness between original and translated text through the use of a 'pure' language which produces the echo of the original" (as cited in Macedo \& Pereira, 2006, p. 13).

A real translation, in light of Benjamin's conception, conveys the intention and the meaning of the original as accurately as possible: "it does not cover the original, does not black its light, but allows the pure language, as though reinforced by its own medium to shine upon the original all the more fully" (as cited in Venuti, 2000, p. 3).

Echoing Benjamin's words, Gayatri Spivak (1992) maintains that the task of the translator is to earn "permission to transgress from the trace of the other ... in the closest places of the self [and] to facilitate this love between the original and its shadow, a love that permits fraying, holds the agency of the translator and the demands of her imagined or actual audience at bay" (as cited in Macedo \& Pereira, 2006, p. 14).

Emphasizing the need for scrupulous attention to the cultural idiosyncrasies of a text and warning against dangerous transgressions, the paper does not claim that the translator should act merely as a walking dictionary, a mere "passer of 
sense" (Meschonnic, 2007, as cited in Venturini, 2011, p.135), or create a pale copy of the original. Rather, while serving as a faithful transmitter of information with utmost fidelity, the translator is permitted to drift from the literalness of the original and not adhere to a word-for-word rendering of a text or making occasional and necessary alterations, transpositions, suppressions, expansions, or embellishments. While being creative, the translator should reconcile faithfulness with freedom in rendering the original text, without an attempt to misrepresent the thought and the cultural setting of the original or falsify the speaker's gender and the poet's intent.

What is of great concern to me, therefore, is a subscription to a translation paradigm where the translator's primary role is to submit to the reality of the author, serve as a mediator between foreign languages and cultures, endeavor to preserve the essence of a foreign culture, and transmit a maximum of the historic, cultural, and aesthetic atmosphere of the original text.

Yet this has not always been this way since some translators, translating a work with no original in mind, violate the ethics of translation - deleting, modifying, or dropping words with little regard to the source text. Since the approach to translation that I favor in this work is specified, what I intend now is to reflect on the particular case of the Arab translation of Shakespeare's Sonnet 18 by Bakri Al- Azzam, Majid Al-Quran, and Mohammed Al-Ali (2010), henceforward referred to as 'the translators.'

\section{Translation as 'Trans-Sica' and 'False Compare'}

The focus of this investigation is the manipulation the Arab translation imposes on Shakespeare's Sonnet 18 in the hope of gaining insight into the workings of three Arab translators that can be seen to transgress the poet's identity and propagate a certain view of Shakespeare's Sonnet 18. In the following, I will try out a reading of the sonnet and its translation from English into Arabic with the purpose of identifying diversions with regard to the original. Admitting that the efforts of the translators to convey the meanings of the original text deserve praise and appreciation, the paper argues that the rendering has serious pitfalls, specifically that it has undermined and subverted the original. In the Arab translation of Shakespeare's Sonnet 18 , it seems clear to me that the original carries no peculiarity or sanctity and that the translators show a strong desire to cathect, dominate, and domesticate the foreign and take freedom in violating, substituting, and eliminating the original. In other words, the Arabic version is a translation with no original, a translation which, while foreign listeners can understand, conceals from them the original meanings of the statements made. In the translation of the sonnet, the translators have somehow succeeded in making this work known to Arab readers, but there is no justification in going so far as to silence the authorial voice or erase the peculiarities of his cultural and aesthetic values.

Pretending to keep the "cultural essence" (Al- Azzam et al., 2010) of the source language text, the translators have not kept strictly to the original and thus have brought to their fellow countrymen a false picture of the foreign author, treated the foreign work as their own text, and altered it according to their own tastes and customs; as such it is brought closer to Arab readers who can then accept it as if it were an original work. Even though the Arabic translation of Sonnet 18 has added to the popularity of Shakespeare in the Arab world, it is my view that this popularization has come with a hefty price - the distortion of the poet's work and teaching; the Arabic creative version does not sound like Shakespeare to someone who can read the sonnet in the original English.

A close reading of the Arab translation makes it possible to observe that the rendering is ruled by a biased cultural framework that determines the translation of the source text, displaces identities, and projects into them new singularities thus granting Shakespeare an Arab voice and providing an image that responds to aesthetic values of Arab readers instead of ascertaining the author's poetics, aesthetic perspective, voice, and identity. Based on this translation paradigm, the translators domesticated the source text values and made them readable for the target language audience by moving the writer toward the reader instead of foreignizing and moving the reader toward the writer. In other words, instead of translating the British culture of the source text and making it known to an Arab audience, the translators opted for a biased cultural translation oriented toward the reader and the target Arab culture.

A further examination of the Arabic translation of Shakespeare's Sonnet 18 shows that, instead of acquainting their countrymen with the sonnet, the translators' interference erased the author's cultural and social idiosyncrasies and presented a culture and a point of view that are not expressed by the foreign author.

There are instances where the Arabic renderings are distorted versions and defective interpretations gone seriously astray from the original text in which the translators acted as version-makers using free hands to interpret however they and their Arab audience wished, according to how they imagined they would like Shakespeare to speak.

Assaulting the author's mother tongue and deleting and adding to the original text indiscriminately in line with their cultural and religious prejudices, the translators endeavored to align the sonnet with the cultural outlook of Arab readers in order not to shock them with the 'immoral' and obscene image where the center of beauty in the sonnet is a young man and not a woman. Thus, the translators made important changes to the speaker's gender and expressed violence by appropriating the beautiful young man and replacing him with a beautiful young Arab Bedouin woman compared to a gazelle and to the moon and surrounded by dates and palm trees. By so doing, the translators diverted and even destroyed the true Shakespearean concept of beauty, took an opposite direction, and built a false image of beauty in a feminine style. Unaware of Shakespeare's fondness for rejecting the traditional concept of beauty as the feature of a blonde white woman, the Arabic version is not improving or doing justice to the original. By introducing an oriental undertone, the translators transformed Shakespeare into an Arab classic poet and tended to show their talents as if they were unwilling to accept the English sonneteer as their master. 
This kind of distortion also applies to the adverbs of time in lines three and four of the translated version of the sonnet. In the original text, Shakespeare mentions two factors that stand behind the fading away of beauty, i.e., "by chance or nature's course untrimmed." In the Arabic text, both 'chance' and 'changing course of time' were dropped in order to preserve the Arabic rhythm and rhyming scheme.

Another example where the translators have violated the original lies in the inaccuracy in presenting the speaker in the sonnet. The speaker in the original is specific: the first-person singular, "Shall I," but in the poetic translation under discussion, the subject is general: "whoever "من ذا".

Based on these remarks, it goes without saying that the kind of changes or "improvements" made by the translators is hardly justifiable and should be viewed as a mistranslation made intentionally and carelessly to achieve fame at the expense of the foreign author. It seems to me that the translators did not translate Shakespeare's sonnet into Arabic because Shakespeare is inaccessible to most of their literate countrymen. Rather, they wanted to show them that Arabic could also do what English could. Likewise, the audience did not read the translation to learn what the original had to say but read the translation to see what the translators had done to the original. By redefining the original, the translators tended to view themselves as geniuses and to place Shakespeare and themselves on a footing of great equality, and thus the translation is read like an original.

In brief, this type of rendering should be viewed as a bad translation, a mistranslation, a crime, and a trans-assassination which, instead of serving the aims of contrastive literature and preserving its future status or being a means of bringing two cultures together, it tears them apart, does harm to the original author, and to his cultural peculiarities and reputation. Consequently, such rendering where the translators domesticate the sonnet and manipulate it to make it work in an Arab society implies that translation represents a threat rather than a blessing for the "afterlife" and the future of contrastive literature.

\section{Conclusion}

To close a circle, the paper has addressed the future directions of comparative literature and re-assessed the role translation can play in the survival of the discipline. Rejecting the view that the point of comparing literary works is to show their superiority or excellence, the study proposes a contrastive literature paradigm where the true task of comparison is to examine and show the resemblances on the one hand, and to contrast in order to reveal and preserve the differences between literatures and cultures on the other. The approach to contrastive literature supported by the present study is a "process that encompasses both sameness and difference, compression and expansion, convergence and divergence, nationalism and internationalism, universalism and particularism" (Vilashini, 2004, p. 14). Based on these premises, the translation paradigm that this study endorses - to better be at the service of the discipline - is not one of mere mediation or transfer of the stable meaning of an original text, neither is it an act of trans-sica of another poet or text according to cultural bias or ideology. It is rather a framework based on the premise that cultures should maintain their essence and identities and where "each word has to be respected and reproduced as things that do not belong to us" (Lamarque in Beaudelaire, 1947, p. 39, as cited in Venturini, 2011, p. 139).

\section{References}

Albright, D. (Ed). (1990). W.B. Yeats: The poems. London: Dent.

Al-Azzam, B., Al-Quran, M., \& Al-Ali, M. (2010). Preserving the cultural essence in translating into Arabic the Shakespeare's sonnet "Shall I Compare Thee to a Summer's Day. "Journal of Language and Literature,1(2), 40-46.

Bassnett, S. (1993). Comparative literature: A critical introduction. Oxford: Blackwell.

Bassnett, S. (2006). Reflections on comparative literature in the twenty-first century. Comparative Critical Studies, 3(12), pp. 3-11.

Benjamin, W. (1923). The task of the translator: Introduction to a Baudelaire translation, 1923(Harry Zohn, Trans). In L. Venuti (ed.), The Translation Studies Reader. London: Routledge.

Bermann, S. (2009). Working in the 'And Zone': Comparative literature and translation. Comparative Literature, 61(4), 432-446.

Bernheimer, C. (Ed.) (1995). Comparative literature in the age of multiculturalism. Baltimore: The John Hopkins Press.

Corngold, S. (2005). Comparative literature: The delay in translation. In S. Berman and M. Wood (Eds.), Nation, Language, and the Ethics of Translation(p. 139-145). Oxford: Princeton University Press.

Crowley, T. (1996). Language in history: Theories and texts. New York: Routledge Press.

Docherty, T. (2006). Without and beyond compare. Comparative Critical Studies, 3(1-2), 25-35.

Guerard, A. (1958). Comparative literature? Yearbook of Comparative and General Literature, 7 (5).

Guillen, C. (1993). The challenge of comparative literature (C. Franzen, Trans). In D. Villanueva, Comparative Literature and Culture, 13(5), 2011.

Macedo, G. \&Pereire, M. (2006). Identity and cultural translation: Writing across the borders of Englishness: Women's writing in English in a European context. Bern: Peter Lang AG, European Academic Publishers. 
Murakami, T.Y. (1998). Don Juan East/West: On the problematics of comparative literature. Albany: State University of New York Press.

Ning, W. (2010). Confronting globalization: Cultural studies versus comparative literature studies? Neohelicon, 28(1), 55-66.

Palencia-Roth, M. (1993). Contrastive literature: Comparative literature in the nineties. A Special Issue of the ACLA Bulletin, 24(2), 47-60.

Saussy, H. (Ed.). (2006). Je ne crois pas beaucoup a la littérature comparée: Comparative literature in an age of globalization. Baltimore: John Hopkins University Press.

Schleiermacher, F. (1999). Des différent s méthodes du traduire et autres textes (A. Bermann and Berner, Trans.). Paris: Seuil.

Tötosy, S. (1998). Comparative literature: Theory, method, application. Amsterdam: Rodopi.

Venturini, S. (2011). Comparative literature and translation: Two Argentinean versions of the Baudelairean spleen. Electronic Journal of Theory of Literature and Comparative Literature, 4, 131-141.

Venuti, L. (1998). The scandals of translation: Towards an ethics of difference. New York: Routledge.

Venuti, L. (Ed.). (2000). The translation studies reader. London: Routledge.

Vilashini, C. (2004). Ghosts in the disciplinary machine: The uncanny life of world literature. Comparative Literature Studies, 41(1), 12-16.

Villanueva, D. (2011). Possibilities and limits of comparative literature today. CLC Web: Comparative Literature and Culture, 13(5).

Yu, P. (2006). Comparative Literature in Question. Daedalus, 135, 38-53.

\section{Appendix}

Bakri Al- Azzam et al.'s Arabic translation of the sonnet:

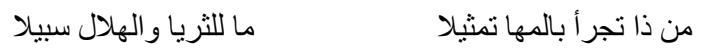

مهما جنت منك الثموس بحر ها بشرور ها هي لن تنال فتيلا

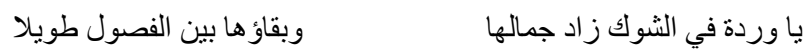

هذا الجمال عن الخلائق راحل ووجودها فيهم يظل رحيلا

لكن حسنك للوجود مصاحب في كل يوم زاده تجميلا

تبقين في عين الجميع حديقة ما دام في أرض الحجاز نخيلا

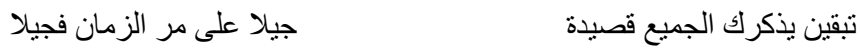

Bakri Al- Azzam et al.’s Back-Translation into English:

Who can dare compare you to a gazelle?

Pleiades and moon haven't any way

However much the hot sun from you does gain

Would have but a stone thread of dates

A rose whose beauty is enhanced by thorns

All the seasons you'll stay alive

From all creatures beauty must depart

So long you betwixt them remain

But your beauty shall this life share

And increase at every dawn of day

All but a garden you shall see

So long as in Hijaz palm trees grow

A poem sung by all you shall be

Throughout the ages year by year. 